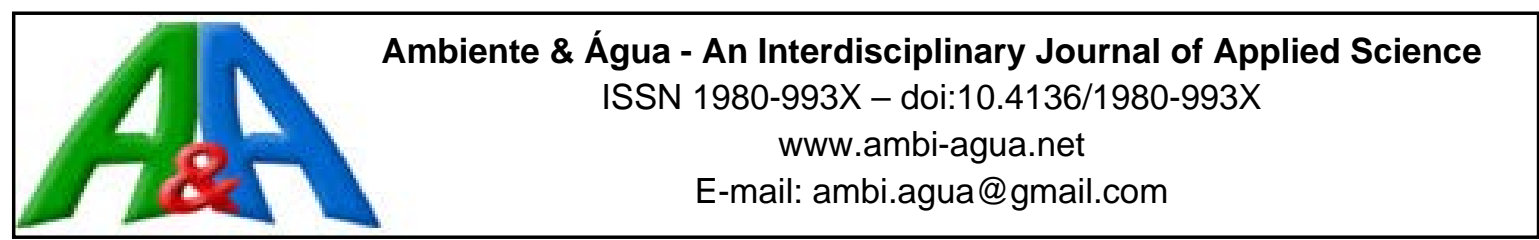

\title{
Efeito das transformações antrópicas às margens do rio Una, Taubaté, São Paulo, Brasil
}

doi:10.4136/ambi-agua.1918

Received: 26 Aug. 2016; Accepted: 11 Oct. 2016

\author{
Marli Aparecida Perim ${ }^{1 *}$; Maria Dolores Alves Cocco ${ }^{1}$ \\ ${ }^{1}$ Universidade de Taubaté (UNITAU), Taubaté, SP, Brasil \\ Programa de Pós-Graduação em Ciências Ambientais \\ *Autor correspondente: e-mail: marliperim@uol.com.br, \\ maria.cocco@unitau.com.br
}

\section{RESUMO}

O presente estudo visa subsidiar o mapeamento de áreas ocupadas às margens de rios com o uso de tecnologias de geoprocessamento de imagens aliadas à aplicação de índices que mesuram os efeitos das transformações antrópicas no ambiente, objetivando verificar a degradação ambiental. O Índice de Transformações Antrópicas (ITA) é comprovadamente eficiente para análises espaço-temporais em bacias hidrográficas e em áreas de proteção ambiental. Com o objetivo de construir uma base de dados para subsidiar as políticas públicas relacionadas à preservação da bacia do rio Una, este artigo traz os efeitos das ações antrópicas nos anos de 1962 a 2014, no bairro de Registro, município de Taubaté, na região metropolitana do vale do Paraíba. Para coleta de dados, com a utilização de fotos e imagens aéreas do território processou-se o georreferenciamento e a vetorização pelo programa QGIS, que possibilitou a quantificação da ocupação e uso do solo. Identificaram-se cinco categorias de tipo de ocupação na área como cursos de água, mata ciliar, campo ou pastagem, mata mais densa e urbanização. Posteriormente aplicou-se o ITA e obteve-se o índice 5,05, que indica uma área degradada, a partir da porcentagem de uso e ocupação do solo. Concluiu-se que a maior mudança ocorreu no espaço temporal de 52 anos, na paisagem do bairro Registro, onde foi observada uma pressão antrópica acentuada, próxima aos cursos de água, em direção a bacia do rio Una, no município de Taubaté, no estado de São Paulo.

Palavras-chave: antropização, bacia hidrográfica, rio Una.

\section{Effects of anthropic transformations on the margins of Una River, Taubaté, São Paulo, Brazil}

\section{ABSTRACT}

This study sought to support the mapping of occupied areas on the margin of rivers through the use of geoprocessing imaging technologies combined with the application of indices that measure the effects of the anthropic transformations in the environment, in order to verify the environmental degradation. The Anthropic Transformation Index is demonstrably efficient for space-time analyses on river basins and at environmental protection areas. In order to develop a data base to support public policies related to the preservation of the Una River Basin, this article presents the effects of the anthropic actions in the years 1962 to 2014, in the registry 
district of Taubaté, in the Vale do Paraíba Metropolitan Region. In order to collect data using photos and aerial images of the territory, geo-referencing and vectorization were performed by the QGIS program, which enabled quantification of the occupation and land use. Five occupational categories types had been identified in the area: watercourses, riparian forest, field or pasture, denser forest and urbanization. Afterwards, the ITA was applied and the index 5.5 was obtained, which indicates a degraded area, based on the percentage of land use and occupation. It was concluded that the greatest change occurred in a 52-year time span, in the landscape of registry district, where a marked anthropic pressure was observed.it is the significant anthropic pressure, close to the watercourses, towards the Una River Basin, in the city of Taubaté, in the state of São Paulo.

Keywords: anthropization, environmental sciences, river basin.

\section{INTRODUÇÃO}

O município de Taubaté, cidade média para os padrões brasileiros, localizada na região metropolitana do vale do Paraíba, no estado de São Paulo passa um processo de rurbanização (Mateus, 2011), significando que os bairros rurais ao longo dos anos vem se transformando em áreas com identidade urbana, mas em detrimento da qualidade ambiental. Este processo no município é consequência, da grande expansão industrial iniciada no ano 1970, no eixo da rodovia Presidente Dutra nos dois sentidos: uma em direção à cidade de São Paulo e a outra no percurso para o município do Rio de Janeiro.

O grau de urbanização do município de Taubaté é de 97,84\%, onde a população rural representa 2,15\% do total (SEADE, 2010). Entre as poucas áreas deste município em que se instala a população rural está o bairro de Registro. Objeto de estudo do artigo, Registro é um exemplo regional de um processo de rurbanização em direção à bacia do rio Una. Afluente do rio Paraíba do sul, o Una é considerado o quarto em importância em abastecimento público de água e taxa de urbanização da bacia hidrográfica do Paraíba do sul (Batista et al., 2002). O crescimento de Registro na área de influência da bacia hidrográfica, apresenta uma autonomia funcional consistente em ter certa paisagem urbana, conteúdo social e uma função transitória de serviços agrícolas e de turismo, que acabam por determinar seus limites físicos junto à rodovia Oswaldo Cruz -SP125 e a calha do rio Una. A rodovia SP125 passou a ser um eixo de integração: do espaço urbano da cidade de Taubaté, da antiga área rural do bairro de Registro e a via de acesso ao litoral norte do estado de São Paulo (Bezerra, 2011).

Segundo Rodrigues (2008) a ocupação urbana gera alterações drásticas nas condições ambientais das bacias hidrográficas pelo aumento das áreas impermeabilizadas nas proximidades dos mananciais. Dessa forma, este artigo se propõe a discutir as transformações na paisagem causadas pelo uso e a ocupação do solo das áreas pertencentes à bacia do rio Una, no trecho do bairro de Registro, tendo como espaço temporal os anos 1962 a 2014. Os efeitos das ações antrópicas foram mensurados por meio de aplicação do Índice de Transformação Antrópica (ITA), tendo como parâmetro os conflitos gerados na paisagem natural por meio da degradação ambiental dos mananciais; aumento do risco de contaminação das áreas de abastecimento pela poluição orgânica e química; e a substituição da mata ciliar por áreas de pastagem.

Segundo Cardoso (2008) a avaliação sob o ponto de vista de ocupação de uma localidade e de sua bacia hidrográfica respectivamente, poderá contribuir para o estudo da vocação urbanística e para o delineamento de futuras propostas de intervenção em uma área, como forma de equilíbrio entre o ambiente construído e o natural, portanto os resultados deste trabalho visa subsidiar as diretrizes do atual plano diretor do município de Taubaté assim como, contribuir 
na elaboração das normas do planejamento da região metropolitana do vale do Paraíba, SP, Brasil.

\section{MATERIAL E MÉTODOS}

O desenvolvimento da metodologia para análise dos efeitos das ações antrópicas, no bairro de Registro, Taubaté/SP, foi baseado nos dados dos órgãos públicos municipais e estadual.

A identificação do espaço temporal (1962-2014) foi realizado por meio de três fotos (EMPLASA, 2015) e duas imagens, 2008 e 2014, capturadas do programa Google Earth, com as seguintes etapas de processamento: (1) preparação da base cartográfica, levando em conta elementos geográficos e morfológicos urbanos; (2) georreferenciamento das fotos e das imagens pelo software QGis, por meio dos pontos de controle a partir de uma das imagens depois do ano 2000; (3) definição da legenda com as categorias a serem vetorizadas identificando-se: cursos de água, mata ciliar, campo ou pastagem, mata mais densa e a urbanização;(4) elaboração de mapas temáticos vetorizados no programa QGis, em que foram calculados os valores das áreas de cada categoria em metros quadrados; e por último (5) a aplicação do Índice de Transformações Antrópicas (ITA) para quantificar as ações antrópicas na área de estudo.

O ITA foi calculado a partir das classes do mapa de uso do solo e de cobertura da terra:

$$
\text { ITA }=\frac{\% \text { uso } X \text { peso }}{100}
$$

em que:

uso = área em valores percentuais da classe de uso e cobertura;

peso $=$ peso dado aos diferentes tipos de uso e cobertura quanto ao grau de alteração antrópica, com a variação de 1 a 10, em que 10 indica as maiores pressões.

Rocha e Cruz (2002) classificaram o ITA em: pouco degradada (0 - 2,5), regular (2,5 - 5), degradada $(5$ - 7,5) e muito degradada $(7,5$ - 10).

Para tanto foi aplicada a classificação do ITA, proposta por Rocha e Cruz (2002), conforme Tabela 1, e os pesos de ITA foram utilizados para cada imagem de acordo com a situação de degradação encontrada.

Tabela 1. Peso para cálculo do ITA.

\begin{tabular}{lc}
\hline Classes & Pesos \\
\hline Pouco degradada & $0-2,5$ \\
Regular & $2,6-5$ \\
Degradada & $5,1-7,5$ \\
Muito degradada & $7,6-10$ \\
\hline
\end{tabular}

Fonte: CRUZ (2002).

A cada classe se apresenta um peso atribuído, em função do conhecimento que o autor tem sobre as mesmas, em relação ao grau de antropização. A atribuição de pesos foi balizada nas seguintes ponderações: (1) a faixa de ITA do 0 ao 2,5, pouco degradada: foi atribuída nos casos em que, apesar de haver ação antrópica, há alteração mínima no recurso natural; (2) a faixa de 2,6 a 5,0, regular: atribuída nos casos de alteração antrópica esperada quando não há planejamento objetivando preservação, mas não há, por outra, degradação acelerada; (3) a faixa de 5,1 a 7,5, degradada: foi atribuída nos casos em que a alteração foi considerável, tendo em vista o período de tempo transcorrido entre uma foto ou imagem analisada; (4) a faixa de 7,6 a

\section{IPABH}

Rev. Ambient. Água vol. 11 (suplemento) Taubaté, 2016 
10,00, muito degradada: foi atribuída às categorias que sofreram uma acentuada ação antrópica em extensão de área e alteração da paisagem.

\section{RESULTADOS E DISCUSSÃO}

A delimitação do bairro de Registro, inexistente em cadastro público municipal, foi elaborada por elementos que compõem a morfologia geográfica e urbana da área: o encontro de cursos de água, o entroncamento de estradas, a existência de propriedades maiores, mas considerando, também, a existência das funções de um bairro. Baseado nos estudos de Bezerra (2011) e Rossi (1995), o desempenho de um bairro apresenta-se como certa autonomia funcional, embora integrada com o espaço urbano total: certa paisagem urbana, indica um conteúdo social e uma função, que acabam por delimitar seus limites. De fato, encontraram-se na abrangência física da área de estudo equipamentos urbanos como escola, posto de saúde e igrejas locais. O levantamento de campo resultou na delimitação do bairro e no mapa com uso e ocupação de solo (Figura 1).

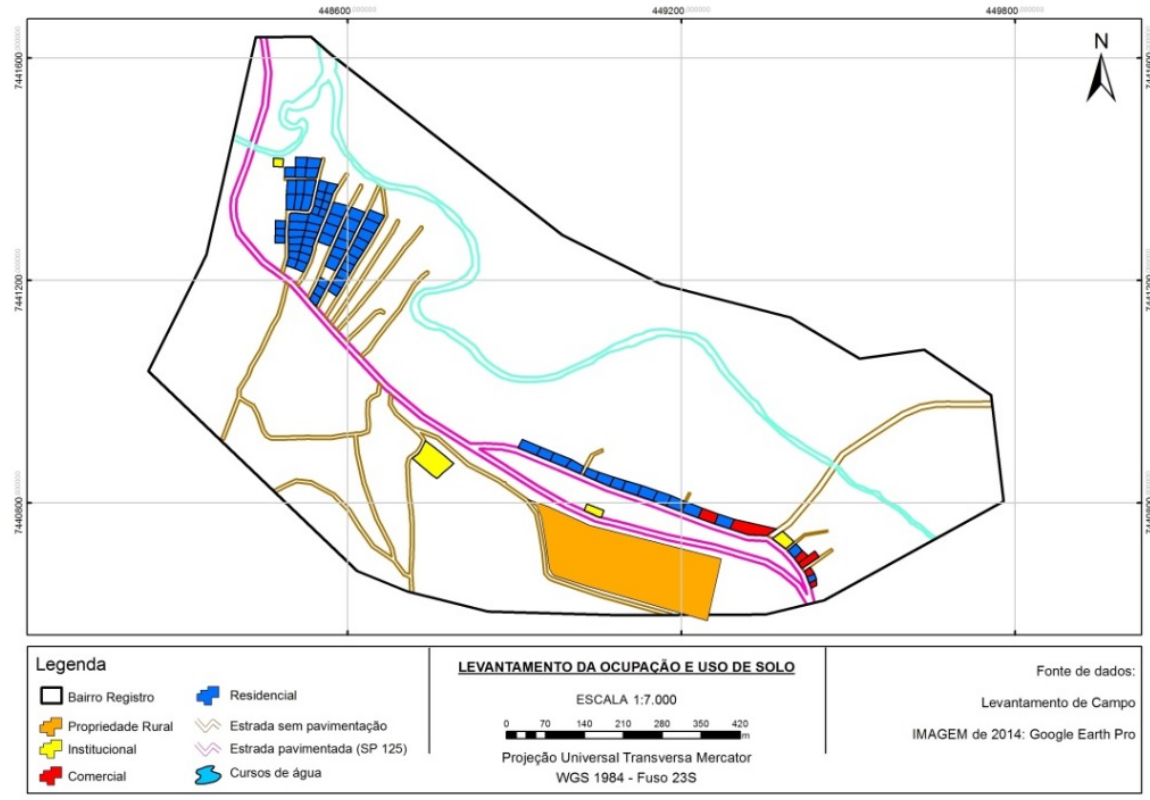

Figura 1. Levantamento de uso de solo do bairro Registro, município de Taubaté, SP, Brasil.

O georreferenciamento das fotos e das imagens aéreas foram tratadas no programa QGis definindo-se pontos de controle a partir de cumes de telhados das construções e ângulos de áreas desmatadas.

Geraram-se polígonos para cada categoria de uso de solo: (1) cursos de água: composta por rios, açudes, lagoas; (2) mata ciliar: cobertura vegetal nativa, que fica às margens de rios, igarapés, lagos, nascentes e represas; (3) área de campo ou pastagem: ocupada ou disponível para cultivo ou pecuária; (4) área de mata: que corresponde a vegetação mais densa; (5) área urbana: conjunto de construções.

As três fotos aéreas, segundo informação da Empresa Paulista de Planejamento Metropolitano/SA (EMPLASA, 2015) têm resolução diferentes: as duas primeiras de 5 metros (ano de 1962 e 1973) e de 9 metros (ano de 1977). As imagens de 2008 e 2014, capturadas do programa Google Earth, têm altitude do ponto de visão de 2 quilômetros, segundo informações da Empresa DigitalGlobe. 
O datum do georreferenciamento utilizado foi o WGS 84 - World Geodetic System 1984, projeção universal transversa mercator, Fuso 23S. Definiu-se a imagem de 2008 como base cartográfica do georreferenciamento. Por meio da ferramenta tabela de Atributos do QGis foi feita a quantificação dos polígonos em metros quadrados, resultando em mapas temáticos de cinco categorias de uso da terra (Figura 2).
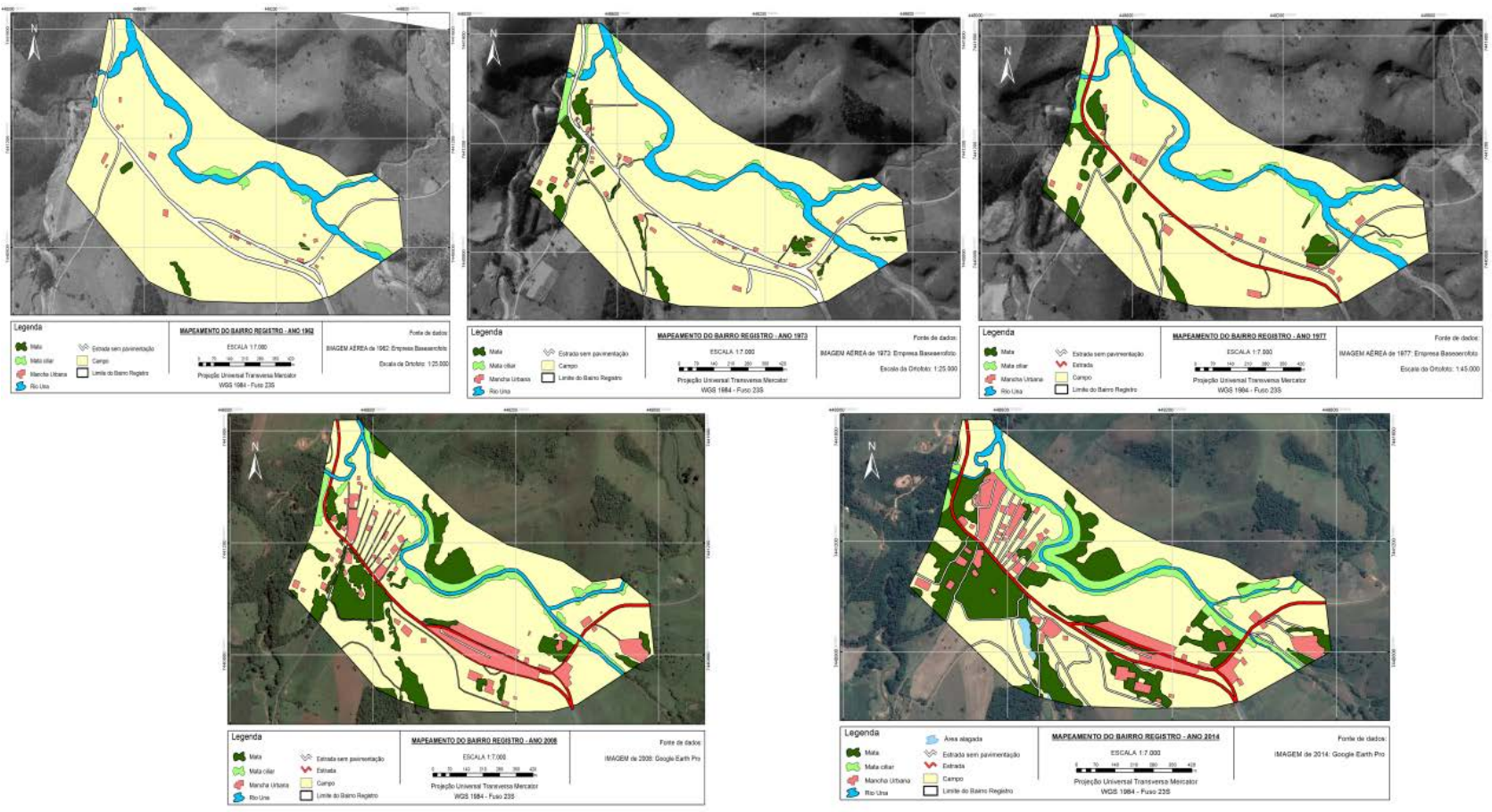

Figura 2. Mapas temáticos de uso e ocupação do solo georreferenciados e vetorizados, bairro Registro, município de Taubaté, SP, Brasil.

Na Tabela 2 se apresenta a distribuição das classes de ocupação da terra entre os anos 1962 e 2014, na área de estudo.

Os dados revelam a crescente ocupação do solo tanto pela mancha urbana de 0,60\% (1962) a 9,20\% (2014), como pela mata ciliar de 1,30\% (1962) a 7,95\% (2014) e a mata com a vegetação mais densa, que ocupava $0,65 \%$ da área e vem crescendo gradativamente chegando ao valor de 21,15\% no decorrer de 2014. Este resultado entende-se como mudança no ciclo de atividade econômica da área, que no seu histórico estava associado às plantações do ciclo de café, a pecuária e a reflexos do crescimento industrial do município, mas que a partir dos meados de 1980 assume sua função transitória de rota turística no sentido do litoral norte do estado de São Paulo.

Tabela 2. Distribuição porcentual de ocupação do uso de solo do bairro Registro, Taubaté/SP.

\begin{tabular}{lccccc}
\hline Categoria & $\begin{array}{c}1962 \\
(\%)\end{array}$ & $\begin{array}{c}1973 \\
(\%)\end{array}$ & $\begin{array}{c}1977 \\
(\%)\end{array}$ & $\begin{array}{c}2008 \\
(\%)\end{array}$ & $\begin{array}{c}2014 \\
(\%)\end{array}$ \\
\hline Cursos d’água & 5,90 & 6,40 & 6,57 & 3,30 & 3,4 \\
Mata ciliar & 1,30 & 1,80 & 2,42 & 5,10 & 7,95 \\
Mata & 0,65 & 3,80 & 5,12 & 12,60 & 21,15 \\
Campo/pasto & 87,50 & 87,00 & 84,85 & 66,70 & 58,30 \\
Área urbana & 0,60 & 1,00 & 1,04 & 7,50 & 9,20 \\
\hline
\end{tabular}


A aplicação do Índice de Transformações Antrópicas (ITA) para quantificar as ações antrópicas na área de estudo foi realizada com base na metragem total de cada categoria e os pesos utilizados que obedeceram ao critério do conhecimento da autora pelas informações históricas e observação das imagens vetorizadas.

A Tabela 3 apresenta a porcentagem de ocupação da categoria cursos de água no decorrer das décadas em pesquisa e o cálculo do ITA, após a aplicação do grau de alteração antrópica. As porcentagens de uso de solo demonstram que os cursos de água, do bairro Registro alteraram negativamente. Isso se deve ao fato da largura dos mesmos ter diminuído. Observe-se que o ITA se revela em crescimento, por conta da menor porcentagem de ocupação, associada a uma maior alteração antrópica.

O trecho do rio Una e das Antas, cursos de água existentes na área de estudo, demonstram que o uso de suas margens, anteriormente para plantio, depois para criação de gado e, mais recentemente, pela expansão urbana irregular e extração de areia em bairros próximos a jusante do rio Una, fizeram com que sua área e consequentemente seu volume diminuíssem consideravelmente. A área ocupada por eles na imagem de 1962 é de 5,9\% e na imagem de 2014 é de 3,4\%.

Tabela 3. Resultado do cálculo do ITA para categoria cursos de água no período de 1962 a 2014.

\begin{tabular}{cccc}
\hline Imagem & $\begin{array}{c}\text { \% uso do } \\
\text { solo }\end{array}$ & $\begin{array}{c}\text { Peso } \\
\text { (grau de alteração } \\
\text { antrópica) }\end{array}$ & $\begin{array}{c}\text { ITA= \%uso X } \\
\text { peso/100 }\end{array}$ \\
\hline 1962 & 5,90 & 2,6 & 0,15 \\
1973 & 6,4 & 2,6 & 0,16 \\
1977 & 6,57 & 2,8 & 0,18 \\
2008 & 3,30 & 7,6 & 0,25 \\
2014 & 3,40 & 7,6 & 0,26 \\
\hline
\end{tabular}

Com relação as porcentagens relativas à ocupação da categoria mata ciliar (Tabela 4) verificou-se que a mata ciliar foi alterada positivamente, mas a ocupação não correspondeu ao crescimento de mata nativa, motivo pelo qual o ITA foi alterado para indicar crescente transformação antrópica.

O ressurgimento da mata ciliar se explica pelo fato da agricultura ter sido substituída, no decorrer das décadas de 70 e 80 pela criação de gado e, a partir da década de 1990, pelo loteamento de terrenos, próximos às margens em alguns trechos apenas do bairro.

Tabela 4. Resultado do cálculo do ITA para categoria mata ciliar no período de 1962 a 2014.

\begin{tabular}{cccc}
\hline Imagem & \% uso do solo & $\begin{array}{c}\text { Peso } \\
\text { (grau de alteração } \\
\text { antrópica) }\end{array}$ & $\begin{array}{c}\text { ITA= (\%uso x } \\
\text { peso/100) }\end{array}$ \\
\hline 1962 & 1,30 & 10,0 & 0,13 \\
1973 & 1,86 & 10,0 & 0,18 \\
1977 & 2,42 & 7,6 & 0,18 \\
2008 & 5,10 & 5,1 & 0,26 \\
2014 & 7,95 & 5,1 & 0,40 \\
\hline
\end{tabular}

Rev. Ambient. Água vol. 11 (suplemento) Taubaté, 2016 
A Tabela 5 apresenta dados sobre a alteração da categoria de mata densa na área de pesquisa, no período estudado. Apesar do crescimento da área ocupada por mata mais densa, o ITA resultou crescente porque o aumento é de mata secundária, sem plano de manejo, em pontos esparsos do bairro, depois que o desmatamento e uso para plantio deu lugar a criação de gado.

Tabela 5. Resultado do cálculo do ITA para categoria mata densa no período de 1962 a 2014.

\begin{tabular}{cccc}
\hline Imagem & \% uso do solo & $\begin{array}{c}\text { Peso } \\
\text { (grau de alteração } \\
\text { antrópica) }\end{array}$ & $\begin{array}{c}\text { ITA= (\%uso x } \\
\text { peso/100) }\end{array}$ \\
\hline 1962 & 0,65 & 10,0 & 0,06 \\
1973 & 3,70 & 10,0 & 0,37 \\
1977 & 5,12 & 5,1 & 0,26 \\
2008 & 12,60 & 5,1 & 0,64 \\
2014 & 21,15 & 5,1 & 1,07 \\
\hline
\end{tabular}

A Tabela 6 demonstra porcentagens sobre a ocupação da categoria campo ou pastagem. A mudança de atividade econômica causou alteração da categoria campo nas imagens após o ano 2000, porque as plantações foram substituídas por criação de gado. O ITA cresceu porque a intervenção antrópica foi muito relevante. A diminuição da área de campo nas imagens vetorizadas indica o crescimento de mata secundária em alguns pontos do bairro, locais que abrigavam plantações e, no decorrer dos anos, não se transformou em área de pastagem, possibilitando o surgimento de árvores de médio porte.

Enquanto na imagem de 1962, 1973 e 1977 a área de campo gira em torno de 85\% da área total do bairro, nas imagens após ano 2000 tem-se uma porcentagem de campo em torno de $60 \%$, decrescendo, e um aumento da porcentagem de mata mais densa e da mata ciliar, em torno de 7 e 21\% respectivamente. Tratando-se de parte de uma bacia hidrográfica é possível identificar a extensão das áreas que são inundadas periodicamente pelo regime de cheias dos rios Una e das Antas para elaboração de um plano de manejo com a seleção das espécies a serem plantadas, objetivando recuperar a mata nativa.

Tabela 6. Resultado do cálculo do ITA para categoria campo ou pastagem no período de 1962 a 2014.

\begin{tabular}{cccc}
\hline Imagem & \% uso do solo & $\begin{array}{c}\text { Peso } \\
\text { (grau de alteração } \\
\text { antrópica) }\end{array}$ & $\begin{array}{c}\text { ITA= (\%uso x } \\
\text { peso/100) }\end{array}$ \\
\hline 1962 & 87,50 & 0,0 & 0,0 \\
1973 & 87,00 & 0,0 & 0,0 \\
1977 & 84,85 & 0,0 & 0,0 \\
2008 & 66,70 & 5,1 & 3,4 \\
2014 & 58,30 & 5,1 & 2,97 \\
\hline
\end{tabular}

O acréscimo significativo de área urbana leva a um cálculo crescente de ITA (Tabela 7), revelando a tendência atual para a área. Como a maioria das cidades médias brasileiras, assim 
classificada Taubaté, não possui planejamento destinado às áreas rurais no sentido de impedir a expansão urbana desordenada e o respeito às regras de preservação ambiental. Por essa razão, os bairros rurais que se estendem às margens da rodovia SP 125, que liga o município de Taubaté ao litoral norte do estado de São Paulo, vêm assistindo um crescimento acelerado e desordenado de construções, mais acentuado no uso residencial. Pela vetorização das imagens observa-se o crescimento da mancha urbana no bairro Registro, na ordem de 6,9\%, de 1977 a 2008, período de 31 anos, e de 1,7\% de 2008 a 2014, período de apenas 6 anos, provavelmente como consequência dá não exigência de aprovação de projeto para a edificação, uma vez que o bairro consta como área rural.

Tabela 7. Resultado do cálculo do ITA para categoria área urbana no período de 1962 a 2014.

\begin{tabular}{cccc}
\hline Imagem & \% uso do solo & $\begin{array}{c}\text { Peso } \\
\text { (grau de alteração } \\
\text { antrópica) }\end{array}$ & $\begin{array}{c}\text { ITA= (\%uso x } \\
\text { peso/100) }\end{array}$ \\
\hline 1962 & 0,60 & 0,0 & 0,0 \\
1973 & 0,95 & 0,0 & 0,0 \\
1977 & 1,04 & 0,0 & 0,0 \\
2008 & 7,50 & 5,1 & 0,38 \\
2014 & 9,20 & 7,6 & 0,69 \\
\hline
\end{tabular}

Após a aplicação do Índice de Transformações Antrópicas (ITA), para quantificar as ações antrópicas na área de estudo, foi possível uma análise quantitativa da dinâmica do uso e ocupação do solo no bairro Registro (Tabela 8). As alterações de ITA encontrados por categoria analisada, obtém-se um número que pode ser considerado do período de 1962 a 2014, da ordem de 5,05, índice que classifica a área degradada, porém não em nível acentuado, uma vez que o índice de 5,05 está próximo do limite da tabela para degradação considerada regular.

Estas alterações de ITA foram maiores entre os anos de 2008 a 2014, para as categorias mata ciliar, mata mais densa e a área urbana, o que indica uma tendência para degradação em decorrência de ações antrópicas mais acelerada daqui para frente. Em contrapartida, a alteração do ITA para o campo foi negativa porque cessou a ação antrópica anos após 2000. Já a alteração do ITA em relação aos cursos de água foi mais acentuada após a década de 1970 e depois da inauguração da estrada SP 125, em que se acentuou a urbanização.

Tabela 8. Análise quantitativa da dinâmica do uso e ocupação do solo, no período de 1962 a 2014, para o bairro de Registro,Taubaté/SP.

\begin{tabular}{lcc}
\hline Categoria & Alteração (\%) & Alteração do ITA \\
\hline Cursos d'água & 2,5 & 0,11 \\
Mata ciliar & 6,65 & 0,27 \\
Mata & 20,50 & 1,01 \\
Campo/pastagem & $-29,50$ & 2,97 \\
Área urbana & 8,6 & 0,69 \\
\hline
\end{tabular}

\section{CONCLUSÃO}

A determinação do nível de transformação antrópica pelo ITA e a aplicação do índice com base nas informações dos diferentes mapas temáticos possibilitam a geração de uma síntese da

Rev. Ambient. Água vol. 11 (suplemento) Taubaté, 2016 
dinâmica espaço-temporal da ocupação e uso da terra, principalmente em áreas que passam pelo processo de rurbanização.

A metodologia aqui desenvolvida poderá ser uma relevante ferramenta para fornecimento de dados ao setor de planejamento urbano e índice de acompanhamento para os planos de recuperação de áreas degradadas.

Destaca-se neste estudo a importância de se conhecer e quantificar as áreas de índice das ações antrópicas por categorias, para melhor identificação no território da área que está sofrendo a maior pressão ou desrespeito aos limites considerados satisfatórios pela legislação.

Sendo assim, conclui-se que a maior mudança ocorrida no espaço temporal de 52 anos, na paisagem do bairro Registro foi a pressão antrópica acentuada, predominantemente sobre a área de preservação próxima aos cursos de água, consistente na alteração de produção agrícola para acelerada expansão urbana e consequente impermeabilização do solo, em direção a bacia do rio Una, no município de Taubaté, no estado de São Paulo.

\section{REFERÊNCIAS}

BEZERRA. J. A. Como definir o bairro? Uma breve revisão. Revista GEOTemas, v. 1, n. 1, p. 21-31, 2011.

BATISTA. G. T.; TARGA. M.; FIDALGO E. C. C. Banco de dados ambientais da Bacia do Rio Una, Bacia do Rio Paraíba do Sul. 2002. Disponível em: https://goo.gl/6L5NPb. Acesso em: dez. 2016.

CARDOSO, A. S. Desenvolvimento de metodologia para avaliação de intervenção em cursos de água em áreas urbanas. 2008. Dissertação (Mestrado Saneamento, Meio Ambiente e Recursos Hídricos) - Escola de Engenharia, Universidade Federal de Minas Gerais, Belo Horizonte, 2008.

EMPRESA PAULISTA DE PLANEJAMENTO METROPOLITANO - EMPLASA. Website. Disponível em: http://www.emplasa.sp.gov.br. Acesso em: 22 maio 2015.

FUNDAÇÃO SISTEMA ESTADUAL DE ANÁLISE DE DADOS - SEADE. Website. 2010. Disponível em: http://www.seade.gov.br. Acesso em: 25 set. 2015.

MATEUS, M. de L. R. O rural em mudança - breve nota sobre os processos de urbanização. Coimbra: Imprensa da Universidade de Coimbra, 2011. http://dx.doi.org/10.14195/978-989-26-0244-8_73

ROCHA, S. P. da; CRUZ, C. B. M. Monitoramento da cobertura vegetal nas APAs da Mantiqueira e Serrinha do Alambari, no Município de Resende com auxílio do Sensoriamento Remoto. In: ENCONTRO NACIONAL DE GEÓGRAFOS, 13., 2002, João Pessoa. Anais... João Pessoa: UFPB, 2002. p. 357.

RODRIGUES, A. S. de L.; MALAFAIA, G.; AMORIM, P. de T. C. Avaliação ambiental de trechos de rios na região de Ouro Preto-MG através de um protocolo de avaliação rápida. REA - Revista de estudos ambientais, v. 10, n. 1, p. 74-83, 2008.

ROSSI, A. A arquitetura da cidade. São Paulo. Martins Fontes, 1995. 